\title{
Electron transfer reactions to 1-adamantyl-, 1-norbornyl chlorides, and their oxo derivatives. A theoretical study
}

\author{
Adriana B. Pierini,* Ana N. Santiago, Simón G. Allende, and D. Mariano A. Vera \\ INFIQC - Departamento de Química Orgánica - Facultad de Ciencias Químicas - Universidad \\ Nacional de Córdoba - Ciudad Universitaria - 5000 Córdoba-Argentina \\ E-mail: adriana@dqo.fcq.unc.edu.ar
}

Dedicated to Professors Roberto A. Rossi and Edmundo A. Rúveda

(received 10 Sep 03; accepted 21 Oct 03; published on the web 30 Oct 03)

\begin{abstract}
The neutral and anionic surfaces of bicyclo[2.2.1]hepta-1-yl chloride (1-chloronorbornane 9), 1chloroadamantane (4), 2-oxo- (10) and 3-oxo-1-chloronorbornane (11), and 5-chloroadamantan2-one (5), were explored at the B3LYP DFT and at the MP2 levels. The studies explain the relative reactivity of these compounds in electron transfer (ET) $\mathrm{S}_{\mathrm{RN}} 1$ reactions mainly in relation to the position of the oxo substituent on the rigid bridge. The reactivity related to the ET dissociation of the unsubstituted halides 9, 4 and the oxo derivatives 10, 11 can be explained through a concerted-dissociative pathway. On the other hand, an stepwise ET mechanism, with radical anions as intermediates, seems the most adequate reaction path to explain the reactivity of compound 5. Besides, this pathway can also be followed by compounds $\mathbf{1 0}$ and $\mathbf{1 1}$ under appropriate experimental conditions. The activation energy for the intramolecular-ET through which the radical anions dissociate into radicals follows the order $\mathbf{5}>\mathbf{1 1}>\mathbf{1 0}$ in the gas phase and by simulating acetonitrile as polar solvent.
\end{abstract}

Keywords: Radical anions, 1-chloroadamantane, 1-chloronorbornane, 5-chloroadamantan-2one, oxo-bicyclo[2.2.1]hepta-1-yl chlorides, intermolecular electron transfer, intramolecular electron transfer

\section{Introduction}

The $\mathrm{S}_{\mathrm{RN}} 1$ mechanism is a chain process through which a compound bearing an adequate leaving group is substituted at the ipso carbon by a nucleophile $\left(\mathrm{Nu}^{-}\right)$. Electron transfer $(\mathrm{ET})$ reactions are key steps of the process, which occurs with radical and radical anions as intermediates. ${ }^{1,2}$

The mechanism has been proposed in 1966 by Kornblum ${ }^{3}$ and Russell ${ }^{4}$ to explain the substitution at $\mathrm{sp}^{3}$ carbons of compounds bearing an electron withdrawing group and a suitable 
leaving moiety at the $\alpha$ carbon, and in 1970 by Bunnett et al. to explain the nucleophilic substitution at $\mathrm{sp}^{2}$ aromatic carbons. ${ }^{5}$

In the aliphatic field, the activation of the substrate by electron withdrawing substituents was considered a necessary condition for the compound to be substituted by the ET pathway. However, this belief was modified in the middle 80's when the substitution of 1haloadamantane, an unactivated aliphatic halide, was shown to occur through the $\mathrm{S}_{\mathrm{RN}} 1$ mechanism. ${ }^{6}$ Since then, the scope of the process in the $\mathrm{sp}^{3}$ field has been considerably broadened. ${ }^{1 \text { a,c, } 2}$ Nowadays, it is generally accepted that compounds whose nucleophilic polar substitution is disfavored due to steric and/or strain factors, are adequate substrates for substitution through an ET route. Neopentyl halides, cycloalkyl, bicycloalkyl and polycycloalkyl halides are some of the compounds known to be substituted by this means. ${ }^{\text {a,c, } 2}$

In the propagation cycle of the mechanism the radicals $(\mathrm{R})$, formed by dissociation of the substrate $(\mathrm{RX})$, couple with the nucleophile $\left(\mathrm{Nu}^{-}\right)$to form the radical anion of the substitution product $\left(\mathrm{RNu}^{-}\right)$(eq 1). This is usually an exothermic reaction due to the stability of the radical anion formed. The ET form $\mathrm{RNu}^{-}$to the substrate (eq 2) is then a key step of the cycle as it forms the radicals responsible to propagate the chain.

$$
\begin{gathered}
\mathrm{R}^{\cdot}+\mathrm{Nu}^{-} \longrightarrow \mathrm{RNu}^{-} \\
\mathrm{RNu}^{-}+\mathrm{RX} \stackrel{\text { inter-ET }}{\longrightarrow} \mathrm{RNu}+\mathrm{R}^{-}+\mathrm{X}^{-}
\end{gathered}
$$

As shown in eq 2, it is generally accepted that the ET to aliphatic halides follows a concerted dissociative pathway. In other words, the C-halogen $(\mathrm{C}-\mathrm{X})$ bond dissociates into a radical and the halide anion as the electron is being transferred (inter-DET). ${ }^{7}$

A different mechanistic pathway can be followed when in the intermolecular ET of eq 2, the aliphatic halide bears a $\pi$ acceptor $\left(\mathrm{Ac}_{\pi}\right)$ as substituent. Under these conditions, the ET to the halide may follow a stepwise pathway with formation of a radical anion intermediate (eq 3 ).

$$
\begin{gathered}
\mathrm{RNu}^{-\cdot}+\mathrm{Ac}_{\pi}-\mathrm{RX} \stackrel{\text { inter-ET }}{\longrightarrow} \mathrm{RNu}+\underset{\pi \mathrm{RA}}{\left(\mathrm{Ac}_{\pi}\right)^{-\cdot}-\mathrm{RX}} \\
\mathrm{R}=\text { alkyl }
\end{gathered}
$$

The generation of the radical anion is attributed to the stabilization exerted by the substituent whose $\pi$ system acts as the acceptor center of the incoming electron. This $\pi$ radical anion fragments by an intramolecular dissociative ET to the C-Halogen bond (intra-DET) in a following step, as shown in eq 4.

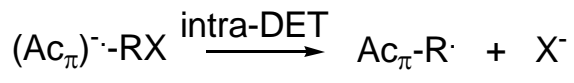

Under conditions of stepwise ET, the intra-DET of eq 4 becomes crucial. While the presence of electron acceptors groups is expected to facilitate the ET to the aliphatic halide (eq 3), the fragmentation of its radical anion depends on electronic and geometrical factors. The number of 
$\sigma$ bonds between the $\pi$-acceptor and the C-X bond ( $\sigma$-acceptor), their relative orientation, and their spatial proximity, are important factors that operate on the efficiency of the intra-DET. Thus, in spite of the fact that the presence of $\pi$ acceptors facilitates the ET from $\mathrm{RNu}^{-}$to $\mathrm{RX}$, this does not necessarily mean that RX will be more reactive towards substitution.

The substitution of the 3,3-dimethyl-bicyclo[2.2.2]oct-1-yl and 2,3,3-trimethyl bicyclo[2.2.1]hepta-1-yl chlorides by an oxo group is an example of the intramolecular redox catalysis exerted by the substituent. While the unsubstituted chlorides do not react with $\mathrm{Ph}_{2} \mathrm{P}^{-}$ ions under irradiation, their 2- and 3-oxo derivatives afford the substituted compounds in high yields under the same experimental conditions. ${ }^{8}$

This experimental behavior has been qualitatively explained on the basis of a facilitated ET to the oxo derivative $\mathbf{1}$ which receives the incoming electron in the carbonyl $\pi^{*}$ MO to form the $\pi$ radical anion. An efficient intra-DET from the $\pi$ acceptor to the $\sigma^{*} \mathrm{C}-\mathrm{Cl} \mathrm{MO}$ forms the bridgehead radical that propagates the cycle (eq 5). ${ }^{8}$

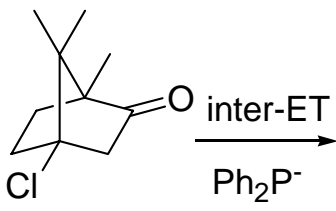

1

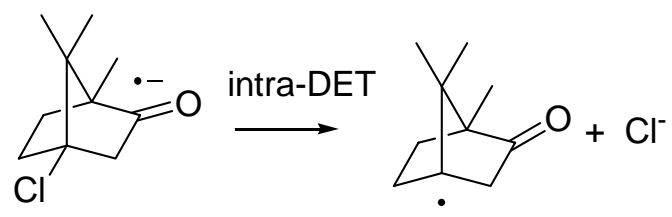

$\pi \mathrm{RA}$

On the other hand, when the rigid bicyclic structure precludes the through bond or through space interaction between the groups, the intra-DET is considerably diminished as in the case of the radical anion of compound 2 which fragments at a lower rate than the $p$-nitrobenzylic analog $3\left(9.3 \times 10^{-3} \mathrm{~s}^{-1}\right.$ vs $\left.\approx 7.9 \times 10^{8} \mathrm{~s}^{-1}\right){ }^{9}$

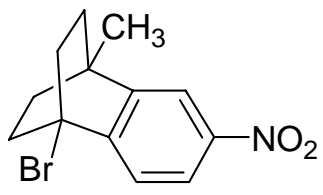

2

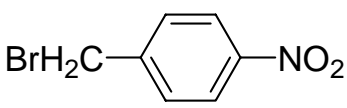

3

Another interesting example of the effect of the relative position of the groups and the rigidity of the bridge is offered by 1-chloroadamantane $(1-\mathrm{AdCl}, 4)$ and its oxo derivative 5chloroadamantan-2-one (5). The relative reactivity of these compounds towards $\mathrm{Me}_{3} \mathrm{Sn}^{-}$has been determined to be equal to 5.3. ${ }^{10}$

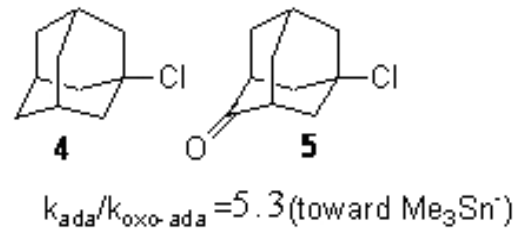


Interestingly, while an oxo substituent at $\mathrm{C}_{\alpha}$ or $\mathrm{C}_{\beta}$ of the 2,3,3-trimethylbicyclo[2.2.1] hepta1 -yl systems has been shown to increase the reactivity of the parent unsubstituted analogs, ${ }^{8 a}$ the oxo substitution at $\mathrm{C} \gamma$ of the adamantyl bridge decreases the reactivity of 5 with respect to 1AdCl. $^{10}$

Besides the concerted dissociative ET and the stepwise pathways, the existence of an effective $\pi-\sigma$ overlap through the bridge is a different factor that has to be taken into consideration. Given this condition, the ET to the compound may follow a dissociative pathway by which the electron is smoothly transferred from the $\pi$ system to the C-X bond through its delocalized $\pi-\sigma$ SOMO.

The phenyl substituted derivatives of the neopentyl family are an example of $\pi-\sigma$ interaction through a flexible bridge. Neophyl chloride (7) has been shown to be 9 times more reactive than neopentyl chloride (6) towards $\mathrm{Ph}_{2} \mathrm{P}^{-}$ions while 1-chloro-2,2-dimethyl-3-phenyl-1-propane (8) has a reactivity similar to that of neopentyl chloride. ${ }^{11}$ This relative reactivity has been explained on the basis of an inter-DET favored for $\mathbf{7}$ which has a C-Cl bond dissociation of lower energy than compounds $\mathbf{6}$ and $\mathbf{8}$. This lowering in energy has been ascribed to the stabilization of the neophyl radical by the phenyl substituent which participates with the $\mathrm{C}$-Cl group in the SOMO of the anionic species. The effect of the phenyl group decreases when it is mediated from the C$\mathrm{Cl}$ bond by an elongated bridge as it is the case for compound $\mathbf{8}$ (Scheme 1). ${ }^{12}$

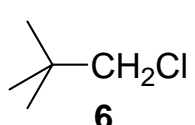

6

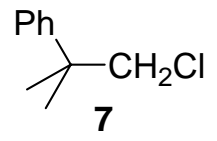

$\pi-\sigma$ assistance

Dissociative ET

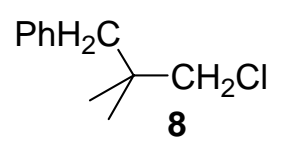

$>>\pi-\sigma$ assistance

\section{Scheme 1}

The $\pi-\sigma$ overlap does not exclude the formation of radical anions which is possible mainly for compounds that bear a highly stabilized $\pi$ system; $p$-nitrobenzyl ${ }^{13}$ and $p$-nitrocumyl ${ }^{14}$ halides being an example of this behavior.

Our main interest was to interpret the effect of $\pi$ oxo acceptors on the bicyclic [2.2.1]hepta1-yl and the polycyclic 1-adamantyl bridges. For a given bridge the effect of the oxo substituent at different positions with respect to the $\mathrm{C}-\mathrm{X}$ bond was taken into consideration. The system studied theoretically includes the unsubstituted compounds 1-AdCl (4), bicyclo[2.2.1] hepta-1-yl chloride (9), and the oxo derivatives 5, 2-oxo-(10) and 3-oxo-bicyclo[2.2.1]hepta-1-yl chloride (11). Our goal was to inspect the preferred mechanistic pathway followed in the intermolecular ET to these compounds. In those cases in which $\pi$ acceptors are present the concerted dissociative vs. stepwise mechanistic possibilities were analyzed as a function of the $\mathrm{C}=\mathrm{O} / \mathrm{C}-\mathrm{Cl}$ distance and on the basis of through bridge and through space interactions. 




4

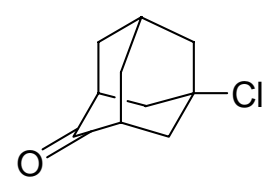

5

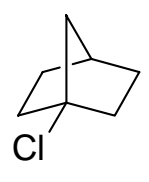

9

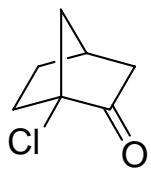

10

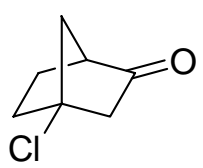

11

The system was evaluated within the $\mathrm{DFT}^{15}$ theory through the B3L YP ${ }^{16}$ functional and with the second order Moller Plesset MP2 method. ${ }^{17}$ The effect of a polar solvent on the gas phase potential energy surfaces was also taken into consideration.

\section{Computational procedure}

The calculations were performed with the Gaussian98 package of programs. ${ }^{18}$ In most cases a preliminary inspection of the potential surfaces was carried out at the unrestricted Hartree-Fock (UHF) level. Afterwards, their exploration with the correlated MP2 formalism and the B3LYP ${ }^{16}$ $\mathrm{DFT}^{15}$ functional was performed varying the selected coordinate with full geometry optimization for the remainder degrees of freedom. All the calculations were performed with the $6-31+\mathrm{G}^{*}$ basis set. This basis set includes diffuse and polarization functions and has been shown to appropriately describe the potential surfaces of radical anionic species. ${ }^{19}$

Previous B3LYP studies have shown this functional to slightly underestimate the energy barrier for the cleavage of $\pi$ radical anions. ${ }^{12}$ For this reason, the $\pi$ zone of the oxo anionic surface was evaluated with the MP2 procedure, which proved appropriate for the localization of this type of intermediates. ${ }^{12}$ The B3LYP functional was employed to study the inter-DET pathway for the whole series of compounds.

In all the cases the MP2 energies were obtained with the projected MP2 (PMP2) method in order to account for the spin contamination in the open shell species. The B3LYP spin contamination of the stationary points as well as along the fragmentation paths was negligible $\left(<\mathrm{S}^{2}>=0.750 \sim 0.751\right)$. The characterization of stationary points was done as usual by Hessian matrix calculations. For key thermodynamic quantities, the energies were improved with the 6$311+\mathrm{G}(2 \mathrm{~d}, \mathrm{p})$ basis and zero point energy corrections were made with the $6-31+\mathrm{G}^{*}$ basis.

The NBO (localized Natural Bonding Orbitals) analyses were performed with the NBO 3.1 standard program from the Gaussian 98 package. ${ }^{20}$ The effect of acetonitrile (MeCN) as a polar solvent was evaluated through the Tomasi's polarized continuum model (PCM) ${ }^{21}$ as implemented in the package. The solvation energies were obtained at the frozen geometries of the gas phase species.

\section{Results and Discussion}


The anionic and neutral potential surfaces of compounds $\mathbf{4 , 5 , 9 - 1 1}$, were evaluated at the B3LYP/6-31+G* level and are presented in Figure 1 for compounds 9 and 11, taken as representative.

The $\sigma$ anionic surface of the unsubstituted chloro compounds $\mathbf{4}$ and $\mathbf{9}$, evaluated at different $\mathrm{C}-\mathrm{Cl}$ bond distances, is dissociative. In other words, no minimum corresponding to a $\sigma$ radical anion was located on this surface with the exception of a shallow one corresponding to a loose complex between the radical and the halide anion formed in the dissociation. ${ }^{22}$

On the other hand, the profiles calculated for the anionic surfaces of the oxo derivatives are characterized by a $\pi$ flat energy region at $\mathrm{C}-\mathrm{Cl}$ distances similar to the equilibrium $\mathrm{C}-\mathrm{Cl}$ bond distance of the neutral and at a slightly elongated C-O distance. ${ }^{\dagger}$

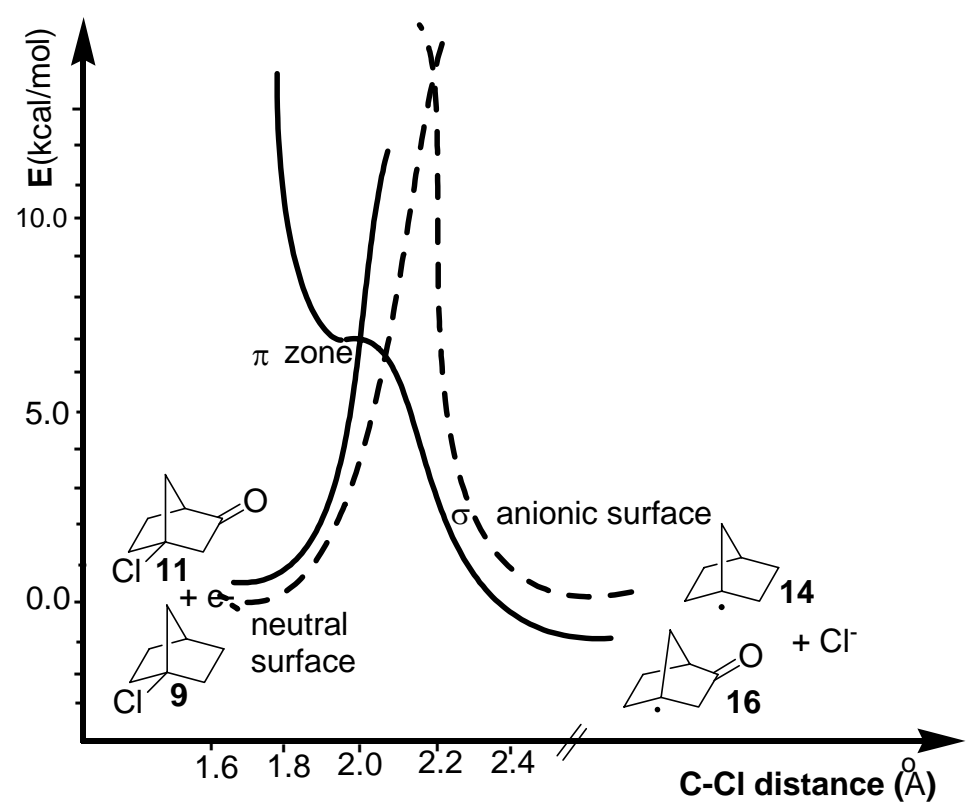

Figure 1. B3LYP/6-31+G* neutral and anionic profiles for compounds 9 (...) and $\mathbf{1 1}(-)$.

According to the model proposed by Savéant, ${ }^{7}$ for a given family of RX, the same leaving group, and similar solvation effects, the diabatic estimate to the activation energy of the interDET can be evaluated from the crossing between the neutral and the anionic surfaces.

The relevant B3LYP information required to analyze the energetic of these reactions is presented in Table 1.

\footnotetext{
${ }^{\dagger}$ This profile could be taken as indicative of the existence of $\pi$ radical anions on the surface of the oxo compounds.
} 
Table 1. Relevant energies $(\mathrm{kcal} / \mathrm{mol})$ and geometry parameters of the inter-DET to aliphatic chlorides

\begin{tabular}{llllll}
\hline & $\mathbf{4}$ & $\mathbf{5}$ & $\mathbf{9}$ & $\mathbf{1 0}$ & $\mathbf{1 1}$ \\
\hline$E_{a}{ }^{a}$ & 12.0 & 5.6 & 14.3 & 6.0 & 6.6 \\
$\Delta E\left(\mathrm{RX}+\mathrm{e} \rightarrow \mathrm{R}^{*}+\mathrm{X}^{-}\right)^{b}$ & -4.57 & -5.85 & 3.16 & 0.10 & -0.94 \\
$\mathrm{BDE}(\mathrm{R}-\mathrm{X})^{c}$ & 81.20 & 79.92 & 88.93 & 85.87 & 84.82 \\
$\mathrm{LUMO}^{d}(\mathrm{eV})^{d}$ & $4.94\left(\sigma^{*}\right)$ & $4.29\left(\pi^{*}\right)$ & $5.25\left(\sigma^{*}\right)$ & $4.01\left(\pi^{*}\right)$ & $4.05\left(\pi^{*}\right)$ \\
${\text { \% s character } \mathrm{p}_{\mathrm{z}} \text { radical center }}^{e}$ & 8.5 & 12.3 & 18.0 & 19.4 & 18.1 \\
$\mathrm{r}(\mathrm{C}-\mathrm{Cl})(\AA)$ & 1.83 & 1.806 & 1.79 & 1.781 & 1.780 \\
\hline
\end{tabular}

${ }^{a} \mathrm{~B} 3 \mathrm{LYP} / 6-31+\mathrm{G}^{*}$ diabatic estimation of the activation barrier for the gas phase process (RX + e $\rightarrow \mathrm{R}^{\prime}+\mathrm{X}^{-}$), taken from the crossing point of the neutral and anionic surfaces (see fig.1). ${ }^{b}$ Thermochemistry of the latter process (zero point energy corrected). ${ }^{c} \mathrm{C}-\mathrm{Cl}$ bond dissociation energy of the neutral (zero point energy corrected). ${ }^{b, c}$ At the B3LYP/6-311+G(2d,p)//B3LYP/6$31+\mathrm{G}^{*}$ level. ${ }^{d} \mathrm{HF} / 6-31 \mathrm{G}^{*}$ canonical LUMO of the neutral. ${ }^{e}$ From the NBO analysis of the corresponding radical formed by dissociation (UHF/6-31G*): \% $\mathrm{s}$ character of the orbital that holds the unpaired electron ( $0 \%$ corresponds to a pure- non strained $\mathrm{p}_{\mathrm{z}}$ orbital at an $\mathrm{sp}^{2}$ center).

The radicals formed in the dissociation are presented in Chart 1. Their stability, evaluated either from the calculated thermochemistry for the inter-DET or from the bond dissociation energy (BDE) (see Table 1), follows the order $\mathbf{1 4}<\mathbf{1 5}<\mathbf{1 6}<\mathbf{1 2}<\mathbf{1 3}$.

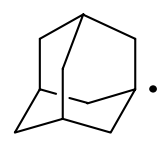

12



13

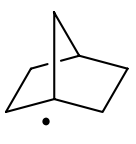

14

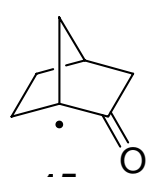

15

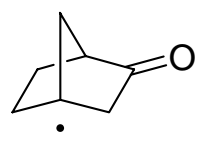

16

\section{Chart 1}

This stability can be rationalized in terms of NBOs analyses. In the adamantyl radical, the orbital holding the unpaired electron has a smaller $s$ character than in the norbornyl case (8.5\% against $18 \%$, Table 1 ). The difference is indicative of the greater strain of the latter radical. ${ }^{23}$ This fact is also evidenced through the NBO analysis of the orbital interactions (perturbative stabilizations) between the radical center (SOMO MO) and the unoccupied MOs of each molecule as shown in Figure 2. The more relaxed structure of $\mathbf{1 2}$ allows for a more effective coupling between the $\mathrm{p}_{z}$ like radical center and the three $\sigma^{*}(\mathrm{C}-\mathrm{C})$ MOs than in the norbornyl case 14. 


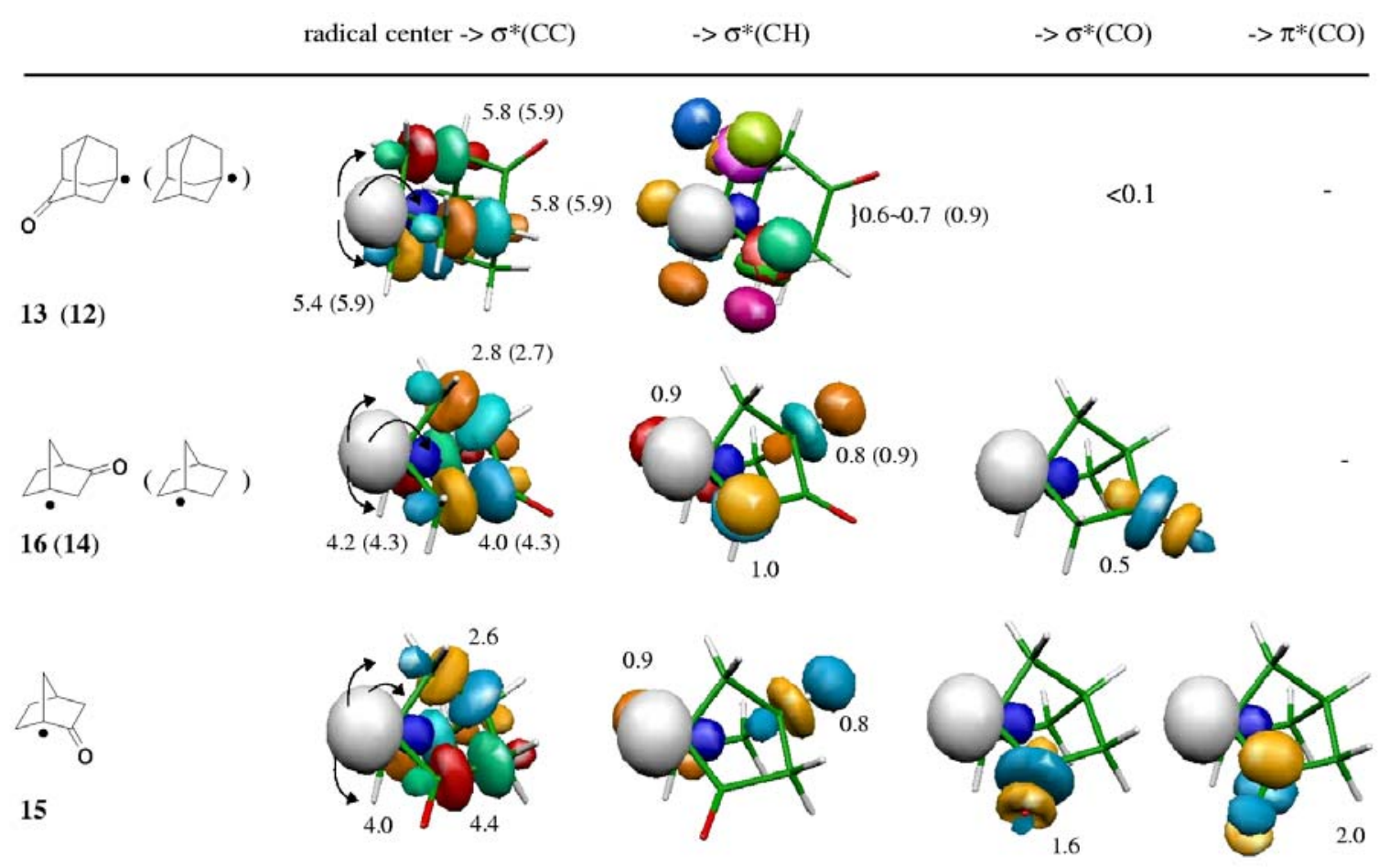

Figure 2. NBO results illustrating the relative stabilization of the different radicals. Main delocalizations of the $\mathrm{p}_{\mathrm{z}}$ like radical center. The only interactions shown are those with perturbation energies greater than $0.5 \mathrm{kcal} / \mathrm{mol}$.

The oxo substitution stabilizes the radicals 13, 15 and 16 due to the field effect exerted by the CO dipole. ${ }^{24}$ Besides, the stabilization of $\mathbf{1 5}$ is reinforced by important orbital delocalizations (perturbations) between the radical center and the carbonyl group (see figure 2). Even though the oxo substitution stabilizes the radicals 15 and 16, its effect does not suffice to overcome the difference in strain energy between the bicyclic [2.2.1] and the polycyclic adamantyl systems and radicals $\mathbf{1 5}$ and $\mathbf{1 6}$ are less stable than radical $\mathbf{1 2 .}$

Based on the model proposed to interpret an inter-DET, ${ }^{7}$ the rate of the reaction, which depends on its $\Delta G^{\circ}$, will reflect the trends observed in the reduction potential (LUMO energy ${ }^{25}$ ) of the compounds. A good correlation between the activation energy of the inter-DET and the LUMO energy was obtained for the whole family of compounds (unsubstituted and oxo substituted ones).

In the inter-DET to an RX that bears a $\pi$ acceptor, the electron is received by the $\pi^{*}$ LUMO which smoothly transforms into $\sigma$ (see neutral-anionic crossing for $\mathbf{1 1}$ in Figure 1). For this type of compounds the rate of the reaction will reflect the energy trends observed in the $\pi^{*}$ LUMOs. On the other hand, in the case of unsubstituted RX the electron is received by a $\sigma^{*} \mathrm{C}-\mathrm{X}$ LUMO. The energy of the $\sigma^{*}$ LUMO and the $\mathrm{C}-\mathrm{X}$ bond dissociation follow the same trend. In agreement with this fact, the dependence of the activation energy of the inter-DET with the stability of the radical formed was established only for the unsubstituted compounds $\mathbf{4 ,} \mathbf{9}$. 
As it is known, the LUMO of unsubstituted polycyclic halides increases with the strain energy of the compound. ${ }^{26}$ Besides, radicals 12 are more stable than radicals 14 , thus, the activation energy for the inter-DET follows the order $\mathbf{4}<\mathbf{9}$. Compounds $\mathbf{5}, \mathbf{1 0}$ and $\mathbf{1 1}$, which have the lowest LUMO, are predicted to dissociate at higher rate than 1-AdCl despite the oxo[2.2.1] radicals $\mathbf{1 5}$ and $\mathbf{1 6}$ being less stable than the 1-adamantyl radical $\mathbf{1 2}$.

At this point the mechanistic steps responsible for the reactivity of compounds in competitive experiments have to be considered. Under conditions of a favored radical-nucleophile coupling step (eq 1), the relative reactivity of a pair of substrates toward a given nucleophile would depend on the relative efficiency of the $\mathrm{k}_{\mathrm{ET}}$ from $\mathrm{RNu}^{-}$toward both alkyl halides, that is on the ratio $\mathrm{k}_{\mathrm{ET} / \mathrm{R} 1 \mathrm{X}} / \mathrm{k}_{\mathrm{ET} / \mathrm{R} 2 \mathrm{X}}$ (eq 6).

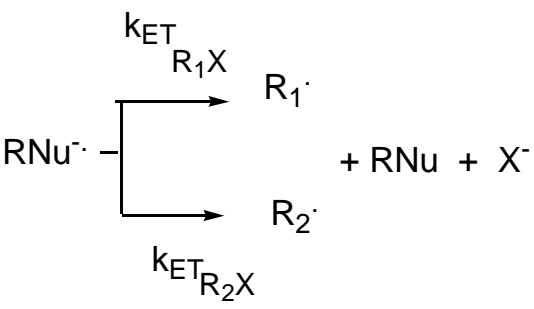

Based on the profiles afforded by the calculations, the reaction will be favored for $4\left(\mathrm{R}_{1} \mathrm{X}\right)$ with respect to $9\left(\mathrm{R}_{2} \mathrm{X}\right)\left(E_{a}\right.$ for inter-DET $12 \mathrm{kcal} / \mathrm{mol}$ vs. $14.3 \mathrm{kcal} / \mathrm{mol}$, Table 1$)$ in agreement with the experimental information. It is known that $\mathbf{4}$ is substituted by $\mathrm{Ph}_{2} \mathrm{P}^{-}$ions under $\mathrm{S}_{\mathrm{RN}} 1$ conditions while $\mathbf{9}$ is unreactive. ${ }^{2 \mathrm{~b}, \mathrm{c}}$ Similarly, the oxo derivatives which dissociate with a lower energy, should be more reactive than the unsubstituted analogs under competition experiments. Experimentally it has been determined that while $\mathbf{9}$ is unreactive, compounds $\mathbf{1 0}$ and $\mathbf{1 1}$ can be substituted by $\mathrm{Ph}_{2} \mathrm{P}^{-}$ions in liquid ammonia. ${ }^{8}$ Moreover, in competition experiments compound 10 has been found 2.8 times more reactive than $\mathbf{1 1}^{8 \mathrm{a}}$ On the basis of an inter-DET 5chloroadamantan-2-one (5) should be more reactive than 1-AdCl (4) ( $E_{a}$ for inter-DET 5.6 $\mathrm{kcal} / \mathrm{mol}$ vs. $12 \mathrm{kcal} / \mathrm{mol}$ ). This theoretical prediction differs from the experimental evidences according to which $\mathrm{k}_{4} / \mathrm{k}_{5}=15$ toward $\mathrm{Me}_{3} \mathrm{Sn}^{-}$in liquid ammonia. ${ }^{10}$ The $\mathrm{k}_{4} / \mathrm{k}_{5}$ value is indicating that other factors have to be taken into consideration to interpret these reactions.

For this reason, the stepwise ET pathway was carefully inspected for $\mathbf{5}$ and the oxo compounds 10 and 11 with the MP2 procedure. $\pi$ Radical anions having the unpaired electron on the carbonyl group were located for the three oxo derivatives with this method. The geometry of these intermediates is presented in Figure $3 \mathrm{~b}$ together with the main geometric parameters of the neutral compounds for comparison purposes (figure 3a). The energy of the intermediates and the energetics of their intra-DET are presented in Table 2.

As shown in figure 3, the main differences between these intermediates and the neutrals are the elongated $\mathrm{CO}$ and $\mathrm{CCl}$ lengths and the dihedral angle between the $\mathrm{C}-\mathrm{O}$ and the $\mathrm{C}-\mathrm{C}_{\mathrm{CO}}-\mathrm{C}$ plane. The carbon of the $\mathrm{C}=\mathrm{O}$ group is clearly $\mathrm{sp}^{2}$ in the neutrals (see the O-C-C-C dihedral angle) and it is outside the $\mathrm{C}-\mathrm{C}_{\mathrm{CO}}-\mathrm{C}$ plane by nearly 60 degrees in the radical anion. The radical character is mainly on the carbonyl carbon and the negative charge on the oxygen (see the electrostatic potential and spin distribution in figure 3b-c). 


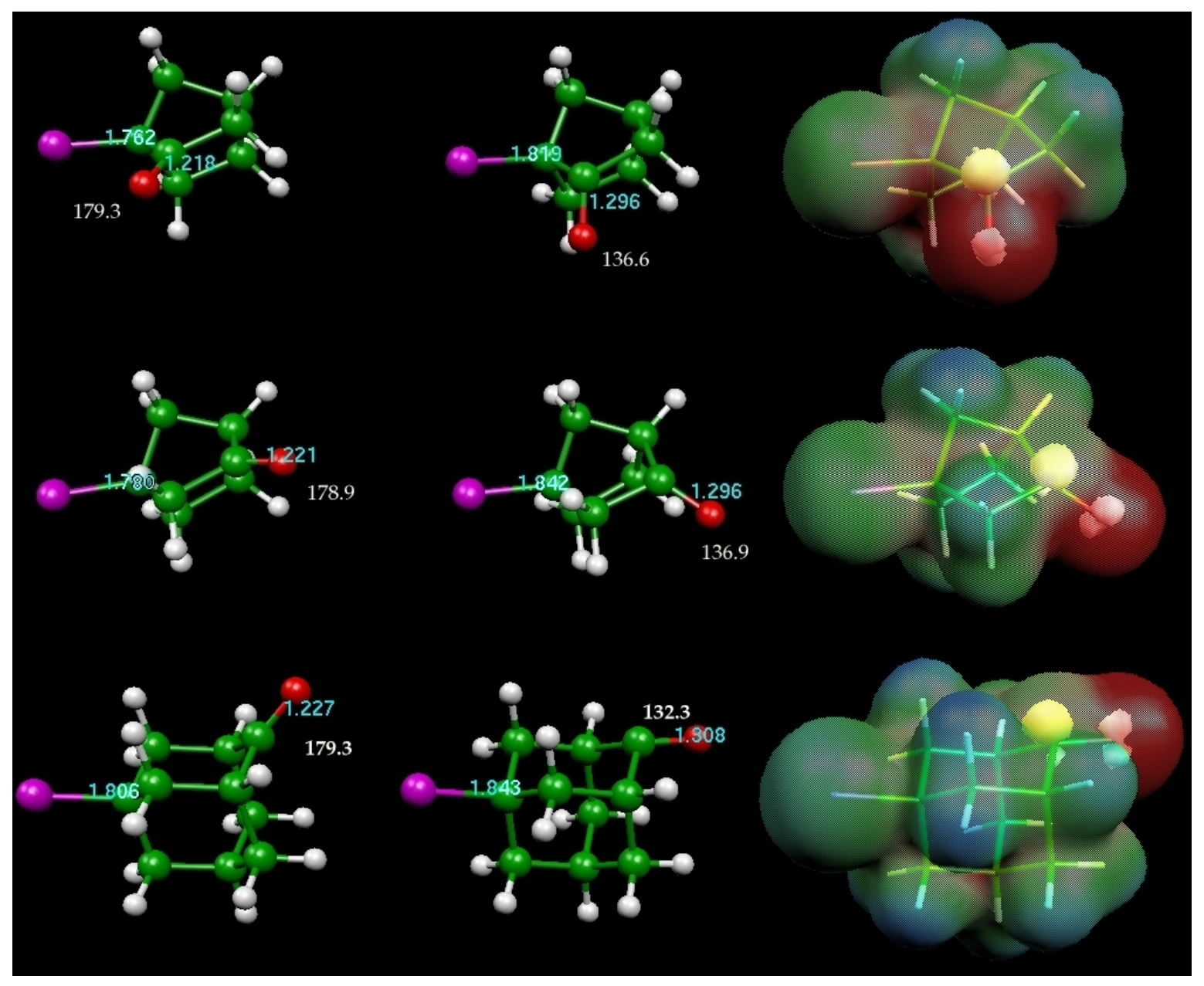

Figure 3. (a) Left column: MP2/6-31G* geometry of 10, 11, and 5 (from top to bottom) indicating $\mathrm{CO}$ and $\mathrm{CCl}$ lengths in angstroms (red and argent respectively) and O-C-C-C dihedral angles (white). (b) Central column: geometry of the corresponding $\pi$ radical anions. (c) Right column: electrostatic potentials (from blue (positive) to red (negative)) on the electron density translucent isosurface of the radical anions; the spin density on the carbonyl group as solid surface.

Table 2. MP2/6-31+G* relevant energies $(\mathrm{kcal} / \mathrm{mol})$ and geometry parameters of the intra-DET within the $\mathrm{C}=\mathrm{O}$ and $\mathrm{C}-\mathrm{Cl}$ groups of bridgehead halides

\begin{tabular}{lccc}
\hline & $\mathbf{5}$ & $\mathbf{1 0}$ & $\mathbf{1 1}$ \\
\hline$E_{a}{ }^{a}$ & $\sim 5$ & 3.21 & 4.43 \\
$\Delta \mathrm{G}_{\text {solv }}(\pi$ radical anion $)$ & -47.95 & -50.20 & -48.92 \\
$\Delta \mathrm{G}_{\text {solv }}\left(\mathrm{TS}_{\text {intra-DET }}\right)$ & & -49.13 & -44.22 \\
\hline
\end{tabular}

${ }^{a}$ Activation energy for the fragmentation of the $\pi$ radical anion $\left(\Delta E^{\neq}\left(\pi \mathrm{RA}->\mathrm{R}+\mathrm{Cl}^{-}\right)\right)$. 
The reaction coordinate for the intra-DET of the radical anion of compound 11, is shown in figure 4 as representative. Note that the transition coordinate involves not only the change in the $\mathrm{CO}$ and $\mathrm{CCl}$ lengths but also the bending of the carbonyl group (the normal mode corresponding to the transition state is shown in figure 4). A similar fragmentation path was found for 10; the barrier being $1.2 \mathrm{kcal} / \mathrm{mol}$ lower.

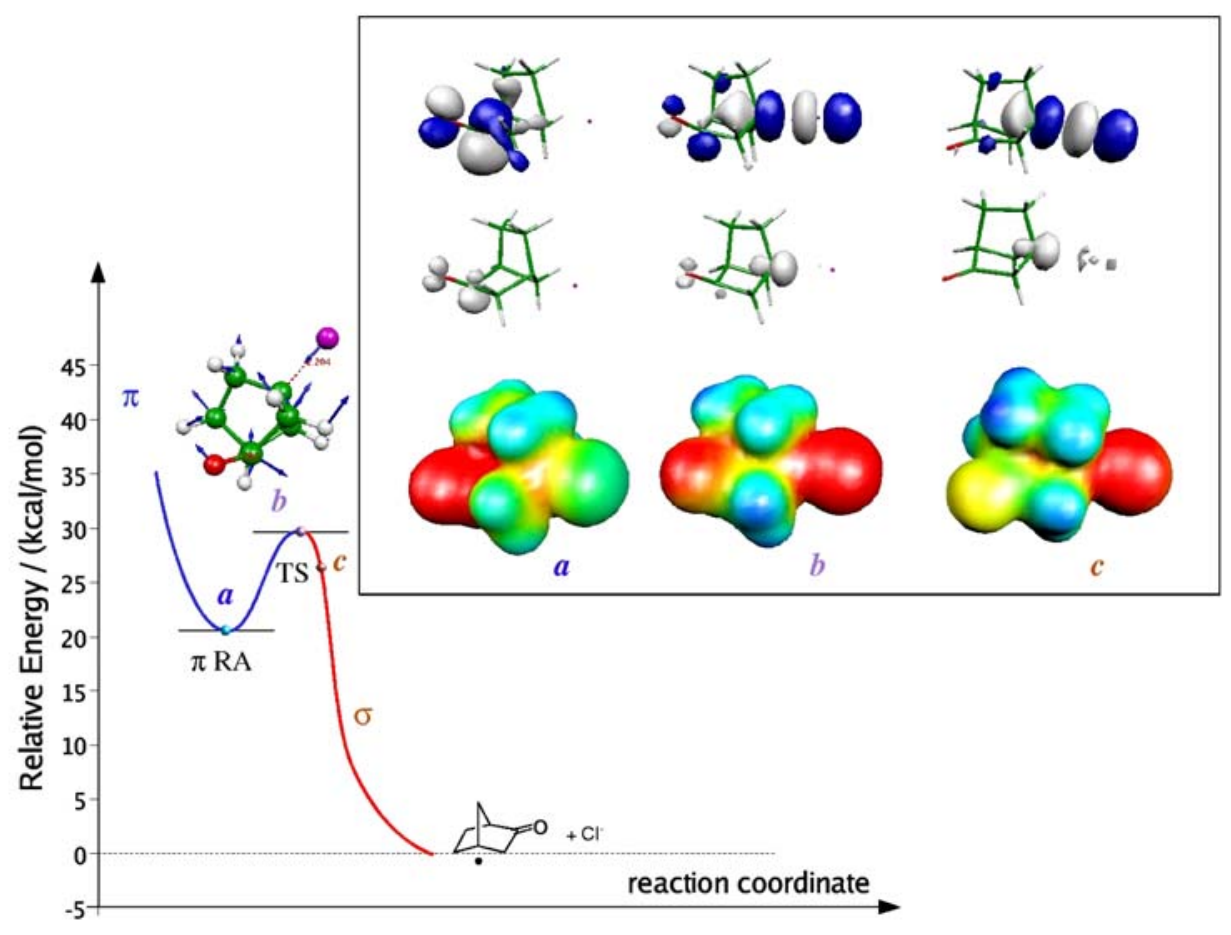

Figure 4. Schematic reaction profile for the $\pi-\sigma$ intra-DET of the $\pi$ radical anion of 11 in MeCN. The SOMO, spin density, and electrostatic potential shown in the upper right box were computed at: (a) the RA minimum; (b) the transition state; (c) at a point of the $\sigma$ surface near the intra-DET TS.

The adiabatic transition states (TS) of $\mathbf{1 0}$ and $\mathbf{1 1}$ can be reached by means of the considerable coupling between the carbonyl $\pi$ system and the $\sigma^{*} \mathrm{C}-\mathrm{Cl} \mathrm{MO}$ (see the SOMO and spin distribution in the TS of the intra-DET for 11, fig. 4b). Unfortunately, the TS for the oxoadamantyl derivative 5 could not be located due to the sharpness of the $\pi-\sigma$ crossing. The activation barrier for the $\pi-\sigma$ intra-DET of 5 was estimated in $5 \mathrm{kcal} / \mathrm{mol}$ from the crossing between both diabatic surfaces. The non-adiabatic character and thus, the low probability of the intra-DET for this compound, is ascribed to the small coupling between the $\pi \mathrm{C}=\mathrm{O} \mathrm{MO}$ and the $\sigma^{*} \mathrm{C}-\mathrm{Cl} \mathrm{MO}$ either through the bridge (through bonds) or through the space, due to the number of $\mathrm{C}-\mathrm{C}$ bonds that separate both centers.

On the basis of the charge distribution shown by the radical anions (charge almost completely localized on the oxygen), the dissociated species (charge on the chlorine atom), and 
the TS (maximum delocalization of the negative charge, see electrostatic potential in fig. 4), it is expected that a polar solvent will stabilize the radical anion and dissociated fragments to a greater extent than the TS. Indeed, this is the case and the activation barrier for the intra-DET of $\mathbf{1 0}$ and $\mathbf{1 1}$ increases in a polar solvent ${ }^{\ddagger}$ (Table 2). A similar increment is expected for compound 5 for which the estimated higher activation barrier is accompanied by the non-adiabatic character of its intra-DET.

The reactivity order $\mathbf{1 0}>\mathbf{1 1}>\mathbf{5}$ predicted by the calculations for the stepwise mechanism holes, both in the gas phase and in solution. This order is in agreement with the experimental information available for $\mathbf{1 0}$ and $\mathbf{1 1}$. Furthermore, it also explains the experimentally determined lower reactivity of $\mathbf{5}$ with respect to $\mathbf{4}$. The inter-ET to $\mathbf{5 , 1 0}$ and $\mathbf{1 1}$ is LUMO-favored with respect to the unsubstituted analogs. From the three oxo compounds $\mathbf{5}$ is a clear example of an assisted inter-ET accompanied by a disfavored intra-DET responsible for its low reactivity.

It is important to take into consideration that the existence of radical anions on a potential surface does not necessarily imply this species as intermediate in ET reactions. The preferred mechanistic pathway followed depends on the relative energy of the $\mathrm{RX}^{-}$and $\mathrm{RNu}^{-}$surfaces which is modified by the donor capability of $\mathrm{RNu}^{-}$. An inter-DET will be followed in those cases in which the first crossing occurs between the $\mathrm{RNu}^{-}$and the $\sigma \mathrm{RX}^{-}$surfaces. On the other hand, an intra-DET becomes the rate determining step of the dissociation when the first crossing occurs between the $\mathrm{RNu}^{-}$and the $\pi \mathrm{RX}^{-}$surfaces, as shown in Figure 5.

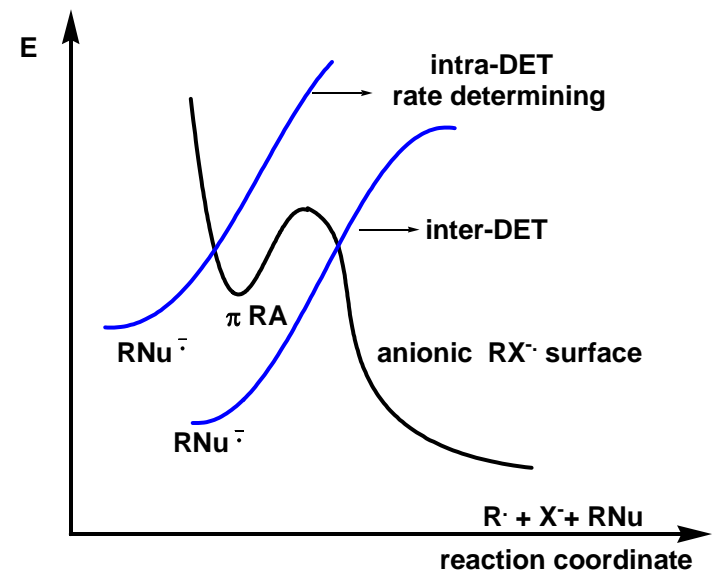

Figure 5. Different mechanistic paths available for the ET from $\mathrm{RNu}^{-}$(-) to $\mathrm{RX}(-)$ as a function of the donor capability of $\mathrm{RNu}^{-}$.

Based on the calculations both, an inter-DET or an stepwise mechanism can explain the relative reactivity of $\mathbf{9 - 1 1}$. On the other hand, it can be concluded that an stepwise mechanism is the preferred pathway followed by 5 under the experimental conditions employed. ${ }^{10}$

\footnotetext{
‡ This stabilization of the $\pi$ intermediate with respect to the TS differs from the behavior observed for the aromatic neopentyl derivative 8. For this compound the small energy barrier of the intra-DET (ca $0.9 \mathrm{kcal}$ ) was not modified by the solvent effect due to the highly delocalization of the negative charge on the phenyl ring.
} 


\section{Acknowledgements}

This work was supported by the Agencia Córdoba Ciencia, the Consejo Nacional de Investigaciones Científicas y Técnicas (CONICET) and SECYT/Universidad Nacional de Córdoba/Argentina.

\section{References}

1. (a) Rossi, R. A.; Pierini, A. B.; Peñéñory, A. B. Chem. Rev. 2003, 103, 71. (b) Rossi, R. A.; Pierini, A. B.; Santiago, A. N. In Organic Reactions; Paquette, L. A.; Bittman, R., Eds.; Wiley: New York, 1999; p 1. (c) Rossi, R. A.; Pierini A. B.; Peñéñory, A .B. In The Chemistry of Functional Groups; Patai S.; Rappoport, Z.; Eds.; Wiley: Chichester, Supl. D2, Ch. 24, 1995, p 1395. (d) Norris, R. K. In Comprehensive Organic Synthesis; Trost, B. M.; Ed.; Pergamon Press, 1991; Vol. 4, p 451. (e) Rossi, R. A.; de Rossi R. H. In Aromatic Substitution by the $S_{R N} 1$ Mechanism; ACS: Washington D.C., 1983. (f) Kornblum, N. In The Chemistry of Functional Groups; Patai S. Ed.; Wiley: Chichester, Supl. F, Ch. 10, 1982; p 361. (g) Bunnett, J. F. Acc. Chem. Res. 1978, 11, 413.

2. (a) Rossi, R. A.; Pierini, A. B.; Palacios, S. M. Adv. Free Rad. Chem.; Tanner, D. D., Ed.; Jai Press, 1990; Vol. 1, p 193. (b) Santiago, A. N.; Martín, S. E.; Rossi, R. A. Trends in Organic Chemistry 2001, 9, 1. (c) Pierini, A. B.; Penénory, A. B.; Baumgartner, M: T. In Electron Transfer Reactions in Organic Synthesis, Vanelle, P., Ed.; Research Signpost: India, 2002, p 63.

3. Kornblum, N.; Michel, R. E.; Kerber, R. C. J. Am. Chem. Soc. 1966, 88, 5662.

4. Russell, G. A.; Danen, W. C. J. Am. Chem. Soc. 1966, 88, 5663.

5. (a) Kim, J. K.; Bunnett, J. F. J. Am. Chem. Soc. 1970, 92, 7463. (b) ibid. 7464.

6. (a) Rossi, R. A.; Palacios, S. M.; Santiago, A. N. J. Org. Chem. 1982, 47, 4654. (b) Palacios, S. M.; Alonso, R. A.; Rossi, R. A. Tetrahedron 1985, 41, 4147.

7. Savéant, J.-M. Adv. Phys. Org. Chem., Tidwell, T. T., Ed., Academic Press, 2000, Vol. 35, p 117.

8. (a) Lukach, A. E.; Morris, D. G.; Santiago, A. N.; Rossi, R. A. J. Org. Chem. 1995, 60, 1000.

(b) Santiago, A. N.; Takeuchi, K.; Ohga, Y.; Nishida, M.; Rossi, R. A. J. Org. Chem. 1991, 56, 1581.

9. Adcock, W.; Andrieux, C. P.; Clark, C. I.; Neudeck, A.; Savéant, J.-M.; Tardy, C. J. Am. Chem. Soc. 1995, 117, 8285.

10. Toledo, C.; Santiago, A. N. Rossi, R. A. J. Org. Chem. 2002, 67, 2494.

11. Duca, J. S.; Gallego, M. H.; Pierini, A. B.; Rossi, R. A. J. Org. Chem. 1999, 64, 2626.

12. Vera, D. M. A.; Pierini, A. B. J. Phys. Org. Chem. 2002, 15, 894.

13. Constetin, C ; Hapiot, P; Medebielle, M.; Saveant, J-M. J. Am. Chem. Soc. 2000, 122, 5623.

14. Constetin, C; Hapiot, P; Medebielle,; Saveant, J-M. J. Am. Chem. Soc. 1999, 121, 4451. 
15. (a) Hohenberg, P.; Kohn, W. Phys. Rev. 1964, 136, B864. (b) Kohn, W.; Sham, I. J. Phys. Rev. 1965, 140, A1133.

16. (a) Lee, C.; Yang, W.; Parr, R. G. Phys. Rev. B 1988, 37, 785. (b) Becke, A. D. Phys. Rev. A 1988, 38, 3098. (c) Miehlich, B.; Savin, A.; Stoll, H.; Preuss, H. Chem. Phys. Lett. 1989, 157, 200.

17. Moller, C.; Plesset, M. S. Phys. Rev. 1943, 46, 618.

18. Gaussian 98, Revision A.7, Frisch, M. J.; Trucks, G. W.; Schlegel, H. B.; Scuseria, G. E.; Robb, M. A.; Cheeseman, J. R.; Zakrzewski, V. G.; Montgomery, J. A. Jr; Stratmann, R. E.; Burant, J. C.; Dapprich, S.; Millam, M.; Daniels, A. D.; Kudin, K. N.; Strain, M. C.; Farkas, O.; Tomasi, J.; Barone, V.; Cossi, M.; Cammi, R.; Mennucci, B.; Pomelli, C.; Adamo, C.; Clifford, S.; Ochterski, J.; Petersson, G. A.; Ayala, P. Y.; Cui, Q.; Morokuma, K.; Malick, D. K.; Rabuck, A. D.; Raghavachari, K.; Foresman, J. B.; Cioslowski, J.; Ortiz, J. V.; Baboul, A. G.; Stefanov, B. B.; Liu, G.; Liashenko, A.; Piskorz, P.; Komaromi, I.; Gomperts, R.; Martin, R. L.; Fox, D. J.; Keith, T.; Al-Laham, M. A.; Peng, C. Y.; Nanayakkara, A.; Gonzalez, C.; Challacombe, M.; Gill, P. M. W.; Johnson, B.; Chen, W.; Wong, M. W.; Andres, J. L.; Gonzalez, C.; Head-Gordon, M.; Replogle, E. S.; Pople, J. A.Gaussian, Inc., Pittsburgh PA, 1998.

19. (a) Vera, D. M. A. Ph.D. Thesis, National University of Córdoba, Córdoba, Argentina, 2001. (b) Pierini, A. B.; Vera. D. M. A. Ab initio Evaluation of Intramolecular Electron Transfer Reactions in Halobenzenes and Stabilized Derivatives. Submitted to J. Org. Chem. 2003.

20. (a) Carpenter, J. E. Ph.D. Thesis, University of Wisconsin (Madison,WI), 1987. (b) Carpenter, J. E.; Weinhold, F. J. Mol. Struct. (Theochem) 1988, 169, 41. (c) Reed, A. E.; Curtiss, L. A.; Weinhold, F. Chem. Rev.1988, 88, 899. Programa NBO 3.1: Glendering, E. D.; Reed, A. E.; Carpenter, J. E.; Weinhold, F. University of Wisconsin.

21. (a) Miertus, S.; Scrocco, E.; Tomasi, J. Chem. Phys. 1981, 55, 117. (b) Miertus, S.; Tomasi, J. Chem, Phys. 1982, 65, 239. (c) Cossi, M.; Barone, V.; Cammi, R.; Tomasi, J. Chem. Phys. Lett. 1996, 255, 327.

22. As previously shown (see ref. 12), these electrostatic complexes disappear or become kinetically unimportant in solution. Hereafter, the discussion will focus on the $\pi$ and $\pi-\sigma$ interconversion zone of the anionic surface.

23. Wiberg, K. B. Angew. Chem., Int. Ed. 1986, 25, 312.

24. A similar effect, due to the effect of the $\mathrm{CCl}$ dipole has been previously observed; see Post, A. J.; Nash, J. J.; Love, D. E; Jordan, K. D.; Morrison, H. J. Am. Chem . Soc. 1995, 117, 4930.

25. Koopmans, T. A. Physica 1993, 1, 104.

26. Pierini, A. B.; Santiago, A. N.; Rossi, R. A. Tetrahedron 1991, 47, 941. 